\title{
Effect of cathodic protection methods on ferrous engineering materials under corrosive wear conditions
}

\author{
F. Brownlie ${ }^{1,2^{*}}$, L. Giourntas ${ }^{1}$, T. Hodgkiess ${ }^{2}$, I. Palmeira ${ }^{1}$, O. Odutayo ${ }^{3}$ A.M. Galloway ${ }^{1}$, A. Pearson ${ }^{2}$ \\ 1: Department of Mechanical and Aerospace Engineering, University of Strathclyde, Glasgow, UK \\ 2: Weir Advanced Research Centre, Glasgow, UK \\ 3: Department of Naval Architecture and Marine Engineering, University of Strathclyde, Glasgow, UK \\ *Corresponding author: f.brownlie@strath.ac.uk
}

\begin{abstract}
Cathodic protection prolongs the service life of fluid transport and offshore engineering components by suppressing corrosion. This study assesses the effect of two cathodic protection methods; impressed current cathodic protection (ICCP) and sacrificial anode cathodic protection (SACP), to three ferrous-based materials in laboratory controlled corrosive wear conditions. The SACP was as effective as ICCP on protection of the low alloy steel and white chromium cast iron under both solid and solid-free corrosive wear conditions. Under solid-liquid impingement, significant reductions in material loss were also observed in both the direct impingement zone and the outer area (oblique angle of attack). This demonstrates the substantial impact of cathodic protection systems that are exposed in erosion-corrosion dominated environments.
\end{abstract}

Keywords: erosion-corrosion, cathodic protection, sacrificial anodes, impressed current, ferrous materials

\section{Introduction}

In fluid transport components, such as pump casings and pipework, corrosive wear has a significant effect on their structural integrity [1, 2]. There are three main components of corrosive wear; mechanical damage, corrosion and the interaction between the two, typically termed as synergy [37]. There are various ways to suppress and possibly mitigate corrosive wear; such as design of the components, selection of corrosion/wear resistant materials/coatings and modification of the environment (such as corrosion inhibitors) [8-10].

One of the most common methods to suppress corrosion-related damage is cathodic protection [11]. Cathodic protection is attained by applying an electrical current, which, if properly controlled, reduces the corrosion rate of the metallic alloy to zero. The external supplied current polarises the entire surface of the material, which is being protected. Therefore, cathodic reactions become the more dominant reaction, while the anodic reactions are suppressed. It is well known, that cathodic protection can mitigate both uniform and localised corrosion. There are two types of cathodic 
protection; impressed current cathodic protection (ICCP) and sacrificial anode cathodic protection (SACP) [12].

ICCP requires a DC source or an AC source with a rectifier along with an inert or expendable auxiliary electrode. Both the metal component and the auxiliary electrode must be exposed to the electrolyte for the cathodic protection to function. Cathodic reactions occur at the surface of the protected component, while the anodic reactions occur at the auxiliary electrode, also known as "anode" in the electrochemical cell. The "target" electrode potential, $E_{0}$, for cathodic protection is the value of the equilibrium electrode potential for the anodic reaction at which potential the rate of the anodic reaction is reduced to zero. At electrode potentials more negative than $E_{o}$, the metal is immune from corrosion. The main advantage of ICCP is its process control over the magnitude of the applied currents in the system and hence the value of the electrode potential imposed on the component to be protected. In cases where the cathodic protection system drives the electrode potential significantly more negative than $E_{0}$, "overprotection" of the component occurs and can lead to hydrogen embrittlement of the protected materials, especially "high strength alloys" [13], along with energy waste.

An alternative cathodic protection methodology is SACP, in which a metallic alloy which is more active than that of the protected metal alloy is utilised to create a galvanic cell. Therefore, the current is supplied by the preferential corrosion of the more active metal, called a sacrificial anode. Common materials used as sacrificial anodes for the protection of steels are zinc-based alloys, aluminium-based alloys and magnesium-based alloys [12]. The advantages of using sacrificial anodes are; easy installation, inexpensive maintenance and low capital cost. The main disadvantages of using sacrificial anodes are that periodic replacement of the anodes during scheduled maintenance may be required and the galvanic current available is dependent upon the sacrificial anode area [14].

In severe erosion-corrosion conditions, a substantial proportion of material loss is by pure mechanical mechanisms - to which cathodic protection (CP) does not apply. Nevertheless, the contribution of corrosion, occurring directly through electrochemical reactions and indirectly via interactive mechanical (termed synergy " $\mathrm{S}$ ") can be significant - depending to an extent on the material [15-17]. Previous studies of the fundamental mechanisms of erosion-corrosion have used ICCP to assess the pure mechanical damage of materials under corrosive wear conditions [18-21]. An obvious pre-cursor to the assessment of the potential of SACP to engineering components, is to demonstrate the ability of SACP to function effectively in corrosive wear applications. Such a reduction in material loss rates would, in some circumstances, provide an adequate extension of the component's life before replacement, especially when the vulnerable part of the component is of 
relatively small surface area. In these engineering applications, SACP would represent a more favourable option compared to ICCP - although this can stop localised corrosion [22]. However, there appears to be limited data about using SACP to eliminate corrosion-related damage mechanisms under corrosive wear conditions.

The aim of this paper is to demonstrate the capability of SACP to minimise the corrosion-related damage occurring in corrosive wear conditions. To demonstrate this feature, three ferrous-based materials; a low alloy steel (UNS G43400), white cast iron $(27 \% \mathrm{Cr} \mathrm{WCI})$ and a superduplex stainless steel (UNS S32760) were assessed in a submerged impinging slurry jet test apparatus. Experiments were conducted under both liquid impingement (LEC - solids free) and solid-liquid (SLEC) conditions. The cathodic protection methods used for the assessment were ICCP, SACP with a zinc-based alloy (SAZN) and SACP with an aluminium-based alloy (SAAA).

\section{Method and Materials}

\subsection{Methodology}

A recirculating submerged slurry impingement test rig (Figure 1) of similar design as discussed previously [19], was utilised in this study. The study consisted of liquid impingement (LEC) and solidliquid (SLEC) submerged impingement tests. The duration of the tests was two hours and the testing conditions were; $3.5 \% \mathrm{NaCl}$ aqueous solution, $39 \pm 1^{\circ} \mathrm{C}$ temperature, jet velocity $17 \mathrm{~m} / \mathrm{s}$ and $90^{\circ}$ impingement angle of attack. Both tests used a nozzle with a diameter of $4 \mathrm{~mm}$ and an offset distance between the nozzle and specimen of $5 \mathrm{~mm}$. The SLEC test solution contained $500 \mu \mathrm{m}$ angular sand particles with a concentration of $450 \mathrm{mg} / \mathrm{l}$. The sand size distribution is illustrated in Figure 2.

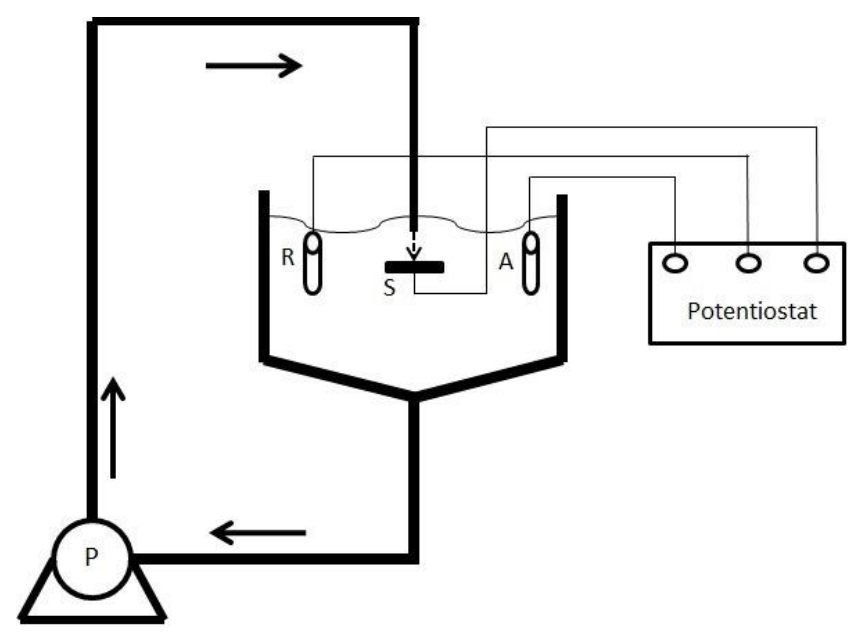

Figure 1: Schematic of erosion-corrosion test rig with potentiostat 


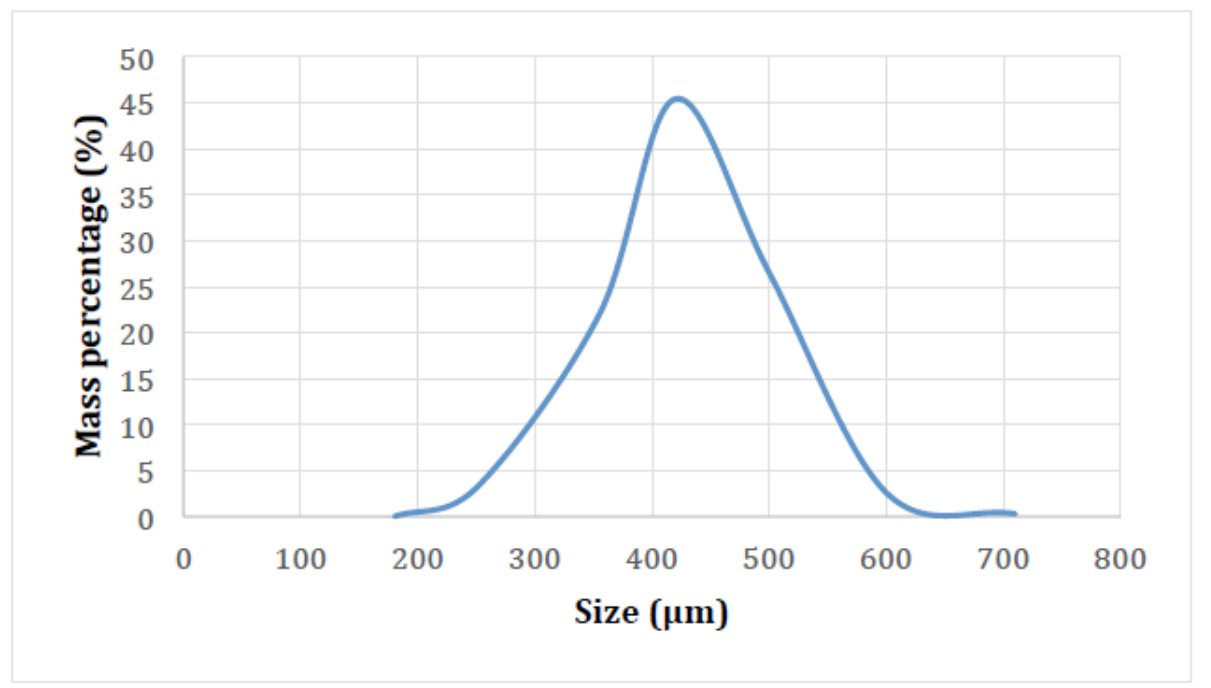

Figure 2: Angular sand size distribution

Both LEC and SLEC tests were conducted in the following conditions; free erosion-corrosion (FEC), impressed current cathodic protection (ICCP) and sacrificial anode cathodic protection (SACP) conditions. In FEC conditions, the materials were exposed to the following degradation mechanisms; mechanical, electrochemical and synergy. To facilitate ICCP conditions, a Gill AC potentiostat (shown in Figure 1), a platinum wire auxiliary electrode and a reference $\mathrm{Ag} / \mathrm{AgCl}$ were utilised to apply an electrode potential of $-850 \mathrm{mV}(\mathrm{Ag} / \mathrm{AgCl})$ on the test materials based on back extrapolation of anodic polarisation plots to the equilibrium electrode potential value. The potentiodynamic polarisation scans, which were conducted for zinc and aluminium anodes, were also conducted with the same potentiostat and three electrode cell. The potentiodynamic scans were conducted 15 minutes after the sample was submerged to allow for the free corrosion potential, $E_{\text {corr }}$, to stabilise. The tests were conducted by shifting the initial potential $20 \mathrm{mV}$ more negative than $\mathrm{E}_{\text {corr }}$ ensuring that the transition point would occur. The scans were then $300 \mathrm{mV}$ more positive than $E_{\text {corr }}$ at a sweep rate of $15 \mathrm{mV} / \mathrm{min}$.

Commercially available aluminium and zinc anodes were employed to develop the SACP conditions. An electrical wire was soldered to the rear side of each sacrificial anode and thereafter it was cold mounted with epoxy resin to ensure that $11.32 \mathrm{~cm}^{2}$ of surface area is exposed to the aqueous solution - equivalent to the surface area of the cathode/test coupon. The specimen holder was modified to accommodate the sacrificial anode next to the test coupon, as shown in Figure 3. The anode and the cathode were connected to each other along with a multimeter and an $\mathrm{Ag} / \mathrm{AgCl}$ reference electrode to monitor their galvanic electrode potentials during the two hour test. 


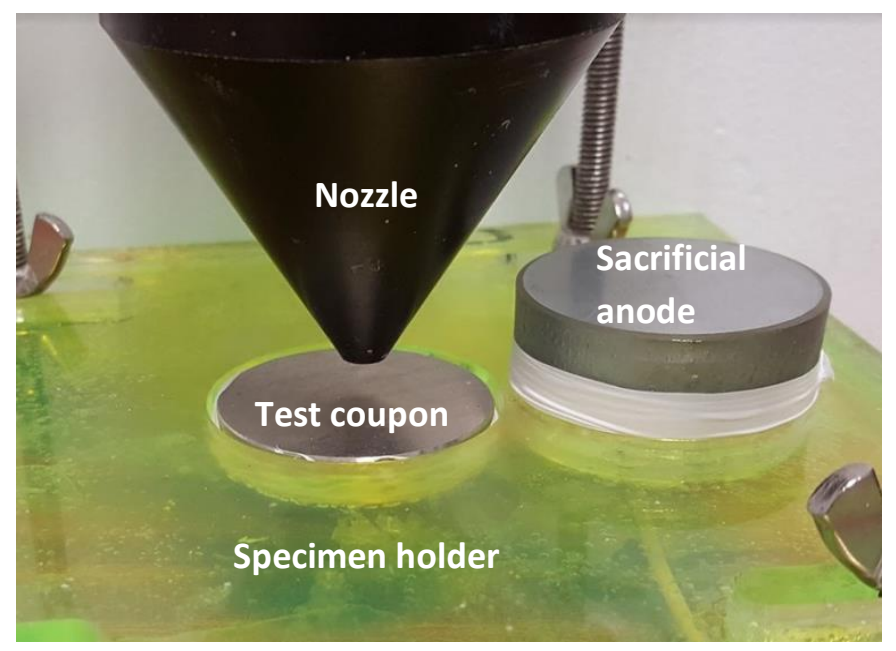

Figure 3: $90^{\circ}$ impingement specimen holder used for SACP tests

Prior to testing, the test samples, along with the encapsulated anodes, were ground to 1200 grit SiC. The volume losses were measured by using a mass balance with $\pm 0.1 \mathrm{mg}$ accuracy and the density of the test materials. Macrohardness measurements were conducted using a Vickers hardness measurement apparatus with a $5 \mathrm{kgf}$ load. Clark's solution was utilised on the post-test samples of low corrosion resistance (i.e. UNS $\mathrm{G} 43400$ and $27 \mathrm{WCI}$ ) to remove the corrosion products before measuring the mass loss. Surface topography of the post-test wear scars was conducted using a noncontacting optical 3D imaging system (Alicona Infinite Focus) which yielded the volume of the wear scar under the directly impinging jet and the outer area with an accuracy of $\pm 0.02 \mathrm{~mm}^{3}$, as discussed in detail in previous work [23].

\subsection{Materials}

The materials which were assessed were a hardened and tempered low alloy steel (UNS G43400 $300 \pm 10 \mathrm{HV})$, a near eutectic white cast iron $(27 \mathrm{WCl}-765 \pm 10 \mathrm{HV})$ and superduplex stainless steel (UNS S32760- 265 $\pm 10 \mathrm{HV}$ ). The zinc and aluminium alloys used for the sacrificial anodes were commercially available grades. The nominal chemical compositions for the low alloy steel, superduplex stainless steel and the sacrificial anodes are given in Table 1 and 2, respectively.

Table 1: Nominal chemical compositions (\%wt) of the materials

\begin{tabular}{|c|c|c|c|c|c|c|c|c|c|c|c|}
\hline Material & $\mathrm{C}$ & $\mathrm{Cr}$ & $\mathrm{Mo}$ & $\mathrm{Ni}$ & $\mathrm{P}$ & $\mathrm{S}$ & $\mathrm{Si}$ & $\mathrm{Mn}$ & $\mathrm{N}$ & $\mathrm{Cu}$ & $\mathrm{Fe}$ \\
\hline UNS & $0.38-$ & $0.70-$ & $0.20-$ & $1.65-$ & 0.0035 & 0.040 & $0.15-$ & $0.60-$ & - & - & Bal. \\
G43400 & 0.43 & 0.90 & 0.30 & 2.00 & & & & & \\
0 & 2.30 & 0.80 & - & & \\
\hline \multirow{2}{*}{$27 \mathrm{WCl}$} & $2.0-$ & $23-30$ & 3.0 & 2.5 & 0.10 & 0.06 & 1.5 & 2.0 & - & 1.2 & Bal. \\
& 3.3 & & max. & max. & max. & max. & max. & max. & - & max. & \\
\hline UNS & 0.030 & $24.0-$ & $3.0-$ & $6.0-$ & 0.035 & 0.02 & 0.80 & 1.20 & $0.24-$ & 0.50 & Bal. \\
S32760 & max. & 26.0 & 5.0 & 8.0 & max. & max. & max. & max. & 0.32 & max. & \\
\hline
\end{tabular}


Table 2: Nominal chemical compositions (\%wt) of the sacrificial anodes

\begin{tabular}{|c|c|c|c|c|c|c|c|c|c|}
\hline $\begin{array}{l}\text { Anode } \\
\text { material }\end{array}$ & $\mathrm{Cu}$ & $\mathrm{Fe}$ & $\mathrm{Cd}$ & $\mathrm{Pb}$ & $\mathrm{Si}$ & $\mathrm{In}$ & Others & $\mathrm{Zn}$ & $\mathrm{Al}$ \\
\hline Zinc & 0.05 & 0.005 & 0.025 & 0.006 & - & - & 0.01 & Bal. & $\begin{array}{c}0.01- \\
0.5\end{array}$ \\
\hline Aluminium & - & - & 0.47 & - & - & - & $\begin{array}{c}0.02 \\
\text { max. }\end{array}$ & 4.5 & Bal. \\
\hline
\end{tabular}

The microstructure images of the three test materials are shown in Figures 4-6. The low alloy steel comprises tempered martensite with retained austenite microstructure (Figure 4). The microstructure of the $27 \mathrm{WCl}$ (shown in Figure 5) demonstrates eutectic chromium carbides (white phase) with eutectic martensite (light brown phase) and primary martensite (dark brown phase). The superduplex stainless steel (Figure 6) has a duplex structure - approximately 50\% austenite and 50\% ferrite.

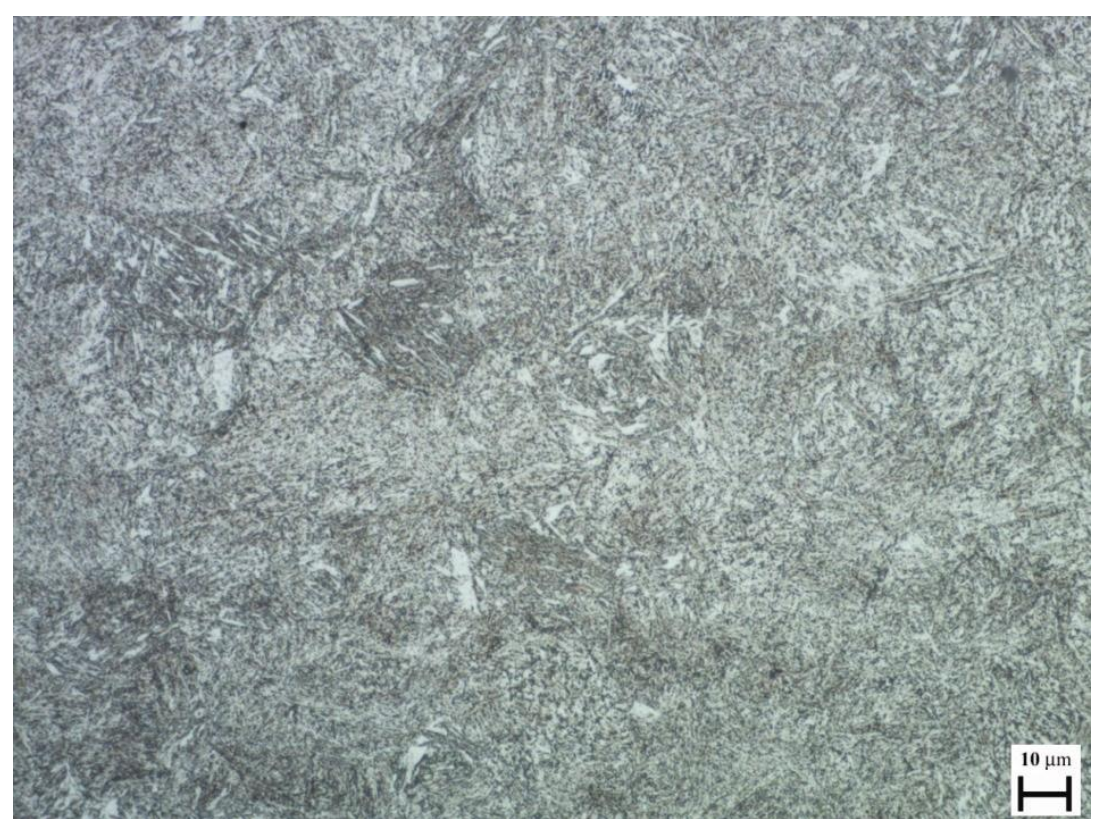

Figure 4: UNS G43400 - tempered martensite with retained austenite 


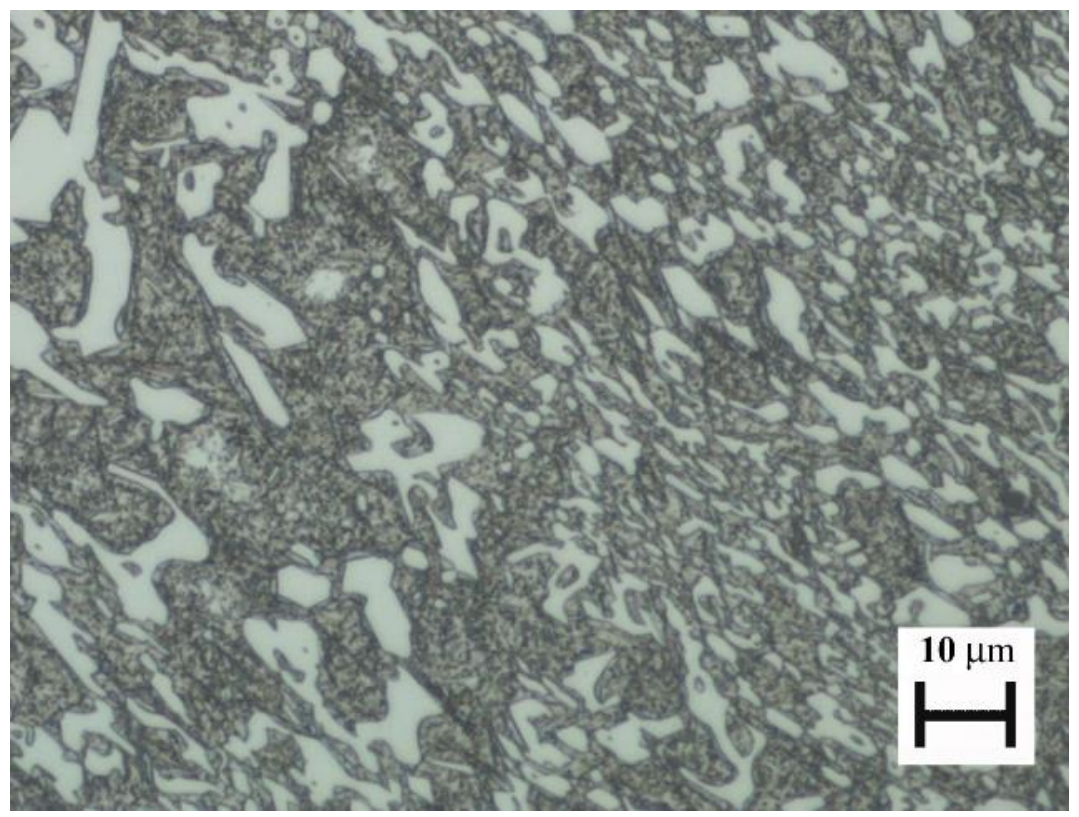

Figure 5: $27 \mathrm{WCl}$ - eutectic matrix and rod like carbides

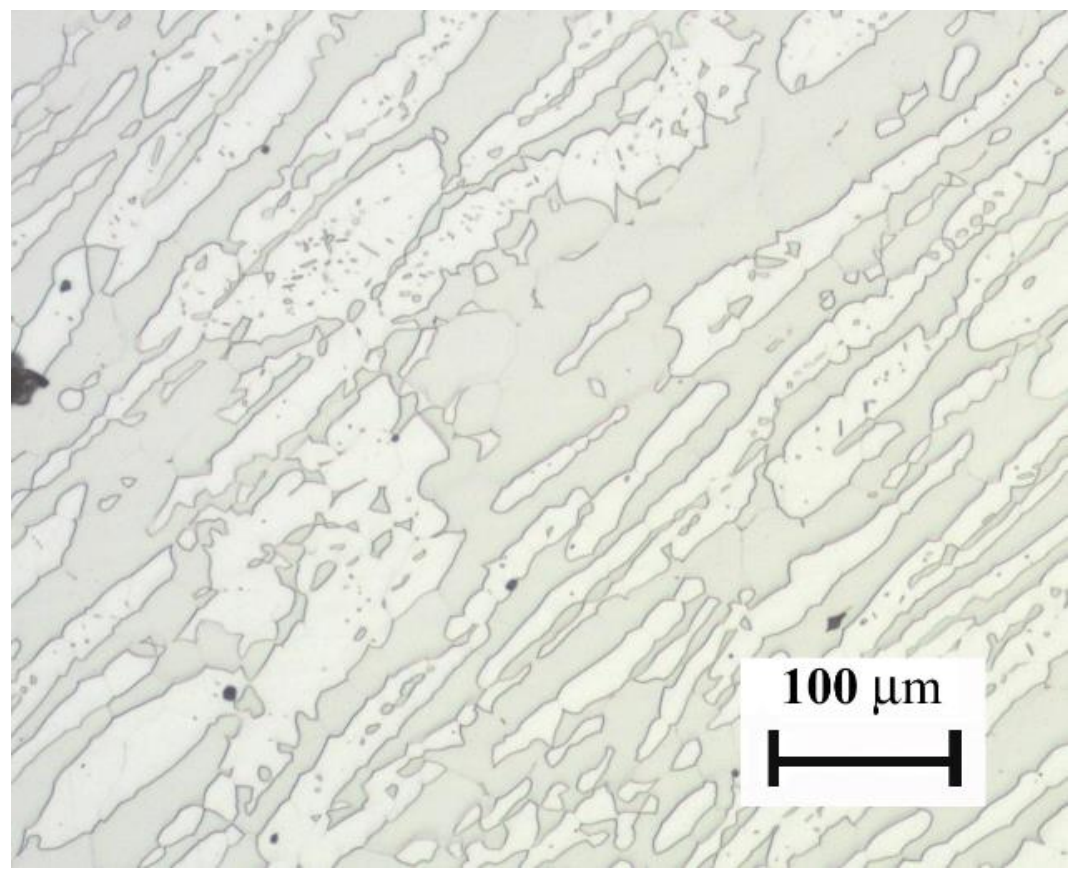

Figure 6: UNS S32760 - austenite-ferrite microstructure

\section{Results and discussion}

\subsection{Cathodic protection in solid-free, liquid erosion-corrosion (LEC)}

\subsubsection{Volume losses in LEC conditions}

Figure 7 displays the volume losses for the test materials with FEC, ICCP, SAAL and SAZN under LEC. The error bands represent the scatter between a minimum of three replicates. In cases where the 
scatter was large, such as on low alloy steel due to its low corrosion resistance, additional test replicates were conducted. Due to the negligible reduction in material loss of the superduplex stainless steel (UNS S32760) when ICCP was applied, it was not tested under the sacrificial anode configuration. The application of cathodic protection has resulted in a volume loss reduction of up to $99 \%$ and $81 \%$ for the low alloy steel and white chromium cast iron, respectively. The remarkable reduction of the volume losses emanates from the fact that under LEC conditions corrosion is the dominant deterioration mechanism. The efficiency of the sacrificial anodes was comparable with the ICCP methodology with deviations lower than $5 \%$. It should be noted that there was scarcely any difference between the protective effect of the two different anode types; Aluminium (98\% reduction in corrosion rate) and zinc (95\% reduction), under LEC conditions, which indicates that both anodes can be used in the field.

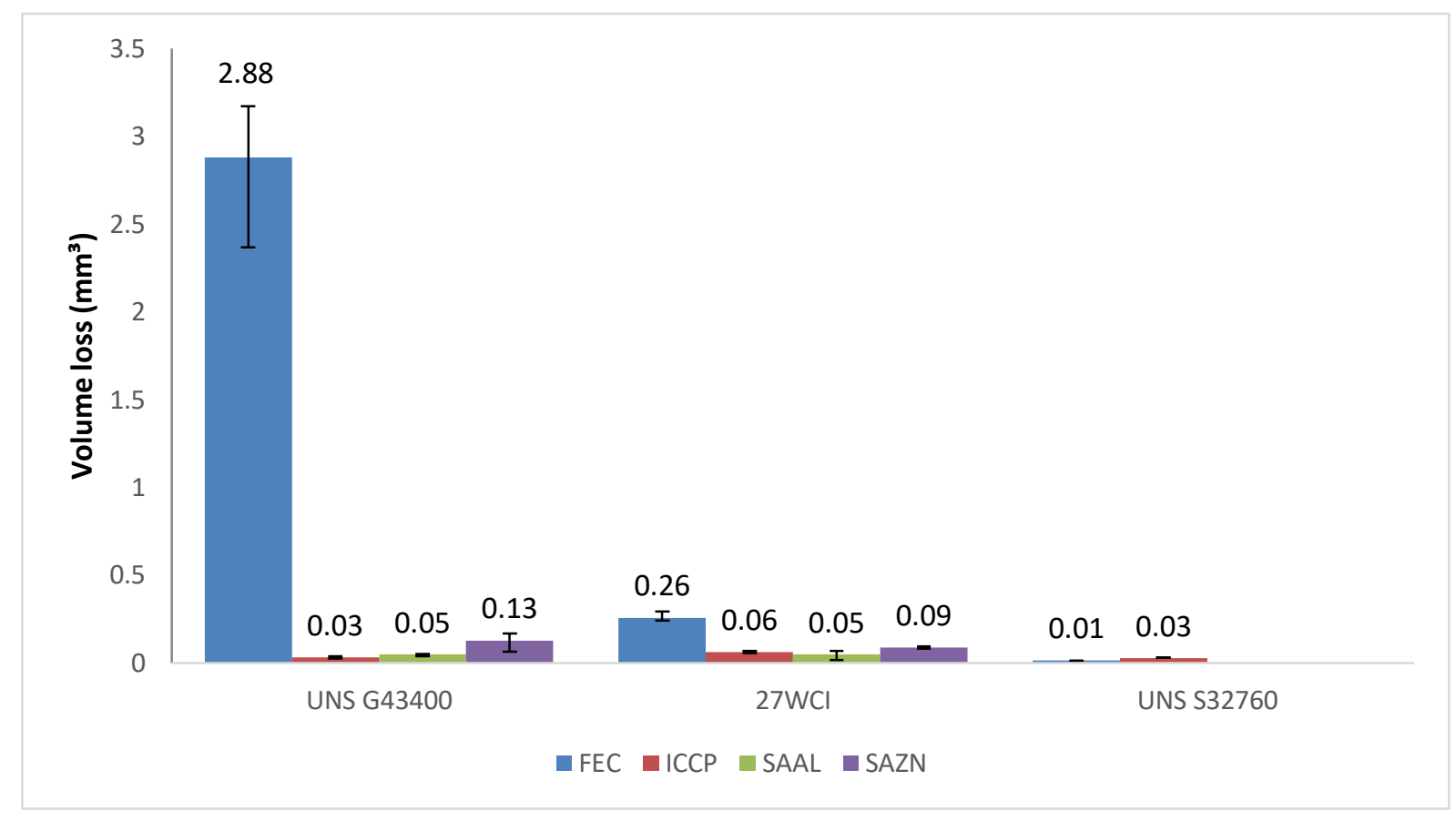

Figure 7: Total volume loss for the test materials under FEC, ICCP, SAAL, SAZN in LEC conditions

\subsubsection{Volume losses in SLEC conditions}

The volume losses are illustrated in Figure 8, which also illustrates how the application of CP enables the superior mechanical wear resistant properties of the white chromium cast iron to be achieved with the performance essentially matching that of the highly-alloyed superduplex stainless steel. Despite the fact that erosion is typically a dominant factor in SLEC conditions, the low alloy steel exhibited a reduction up to $73 \%$ and the white chromium cast iron demonstrated a reduction up to 49\% when CP was applied (Table 3). The percentage reduction in material loss for both materials 
under LEC and SLEC conditions shows the substantial benefit in applying CP under corrosive wear conditions.

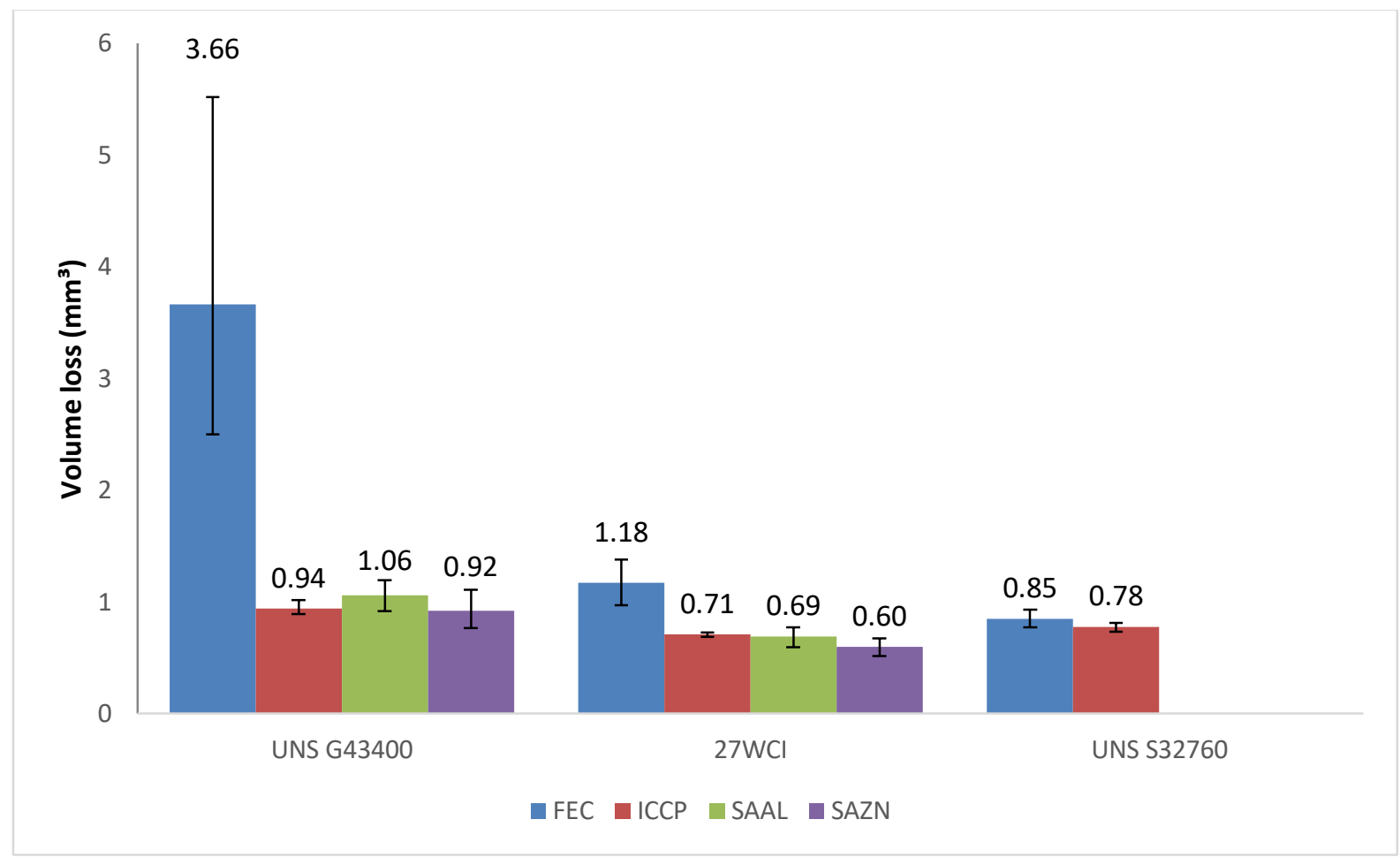

Figure 8: Total volume loss for the test materials under FEC, ICCP, SAAL, SAZN in SLEC conditions

Table 3: Percentage reduction of overall volume loss for the test materials under SLEC conditions

\begin{tabular}{lllll}
\hline & & ICCP & SAAA & SAZA \\
\hline UNS & Full specimen & $73.0 \%$ & $69.4 \%$ & $73.0 \%$ \\
\hline 273400 & Full specimen & $40.5 \%$ & $41.6 \%$ & $49.4 \%$ \\
\hline
\end{tabular}

Two different hydrodynamic wear regions occur during the impinging slurry test - direct impinged zone (DIZ - high angle corrosive wear) and outer area (OA - low angle corrosive wear). As a result, different wear mechanisms occur during the test. Table 4 displays the average volume losses in the DIZ and OA wear regions for the low alloy steel and the near-eutectic white cast iron in FEC and CP environments under SLEC conditions. Table 4 also lists the percentage reduction of the DIZ and OA volume losses for the test materials under SLEC conditions. It can be observed that all CP methods were equally effective in reducing the material loss.

For both the low alloy steel and white cast iron, $C P$ had the highest impact in the $\mathrm{OA}$, where the fluid flow is less turbulent and the abrasive particles have lost kinetic energy which results in less 
mechanical damage. Hence, corrosion-related mechanisms are more prevalent in the OA. The white cast iron also displayed a significant reduction in material loss in the DIZ when CP was applied, this can be attributed to the de-passivation/re-passivation events occurring to the passive oxide film being periodically removed by the impinging particles. There may be a perception that $\mathrm{CP}$ will be relatively less effective in slurry impingement conditions - on account of the significant contribution of mechanical damage. These findings, however, illustrate substantial benefits especially under low angle flow conditions.

Table 4: Average volume losses in DIZ and OA for the test materials in FEC and CP environments under SLEC conditions

\begin{tabular}{|c|c|c|c|c|c|c|c|c|}
\hline \multirow[b]{2}{*}{ Material } & \multirow{2}{*}{$\begin{array}{l}\text { Wear } \\
\text { zone }\end{array}$} & \multirow{2}{*}{$\begin{array}{c}\text { FEC } \\
\left(\mathrm{mm}^{3}\right)\end{array}$} & \multicolumn{2}{|c|}{ ICCP } & \multicolumn{2}{|c|}{ SAAA } & \multicolumn{2}{|c|}{ SAZA } \\
\hline & & & $\begin{array}{c}\text { Volume } \\
\left(\mathrm{mm}^{3}\right)\end{array}$ & $\begin{array}{c}\text { Reduction } \\
\text { (\%) }\end{array}$ & $\begin{array}{c}\text { Volume } \\
\left(\mathrm{mm}^{3}\right)\end{array}$ & $\begin{array}{c}\text { Reduction } \\
\text { (\%) }\end{array}$ & $\begin{array}{l}\text { Volume } \\
\left(\mathrm{mm}^{3}\right)\end{array}$ & $\begin{array}{c}\text { Reduction } \\
\text { (\%) }\end{array}$ \\
\hline \multirow{2}{*}{$\begin{array}{c}\text { UNS } \\
\text { G43400 }\end{array}$} & DIZ & 0.88 & 0.65 & $26.0 \%$ & 0.73 & $17.4 \%$ & 0.65 & $26.0 \%$ \\
\hline & OA & 2.42 & 0.25 & $90.0 \%$ & 0.37 & $84.7 \%$ & 0.31 & $87.4 \%$ \\
\hline \multirow{2}{*}{$27 \mathrm{WCl}$} & DIZ & 0.92 & 0.57 & $29.5 \%$ & 0.56 & $31.1 \%$ & 0.46 & $42.6 \%$ \\
\hline & $\mathrm{OA}$ & 0.32 & 0.14 & $56.0 \%$ & 0.13 & $60.0 \%$ & 0.13 & $60.0 \%$ \\
\hline
\end{tabular}

\subsection{Galvanic potentials}

Table 5 displays the free corrosion potentials, $E_{\text {corr, }}$ for each of the test materials under LEC and SLEC conditions. In both flow conditions, the aluminium sacrificial alloy displayed a slightly more negative free corrosion potential compared to the zinc sacrificial alloy.

Table 5: Free corrosion potentials of materials under LEC and SLEC conditions before galvanic coupling

\begin{tabular}{|c|c|c|}
\hline \multicolumn{1}{|c|}{ Material } & $\mathbf{E}_{\text {corr }}$ LEC (mV) & $\mathbf{E}_{\text {corr }}$ SLEC (mV) \\
\hline UNS G43400 & -531 & --546 \\
\hline 27 WCI & -539 & -461 \\
\hline Aluminium alloy & -1054 & -1123 \\
\hline Zinc alloy & -1037 & -1062 \\
\hline
\end{tabular}

Figure 9 shows the trend in galvanic potentials with time for each of the testing pairs (low alloy steel or white cast iron with aluminium and zinc sacrificial alloys). Each of the galvanic couple potentials became fairly stable after approximately 40 minutes from the beginning of the test. In LEC and SLEC conditions, each coupled potential pair exhibited an electrode potential more negative than the standard target $\mathrm{CP}$ potential of $-850 \mathrm{mv}(\mathrm{Ag} / \mathrm{AgCl})$ [24] - hence, demonstrating the successful application of CP under both test conditions. 
A noticeable difference between the aluminium and zinc sacrificial anode couples is the more negative galvanic potential for the test materials coupled with the zinc sacrificial alloy. This is despite the aluminium sacrificial alloy exhibiting a free corrosion potential which is more negative than the zinc sacrificial alloy. This feature is associated with the more severe anodic polarisation characteristics of the aluminium alloy compared to the zinc alloy, as shown in Figure 10.

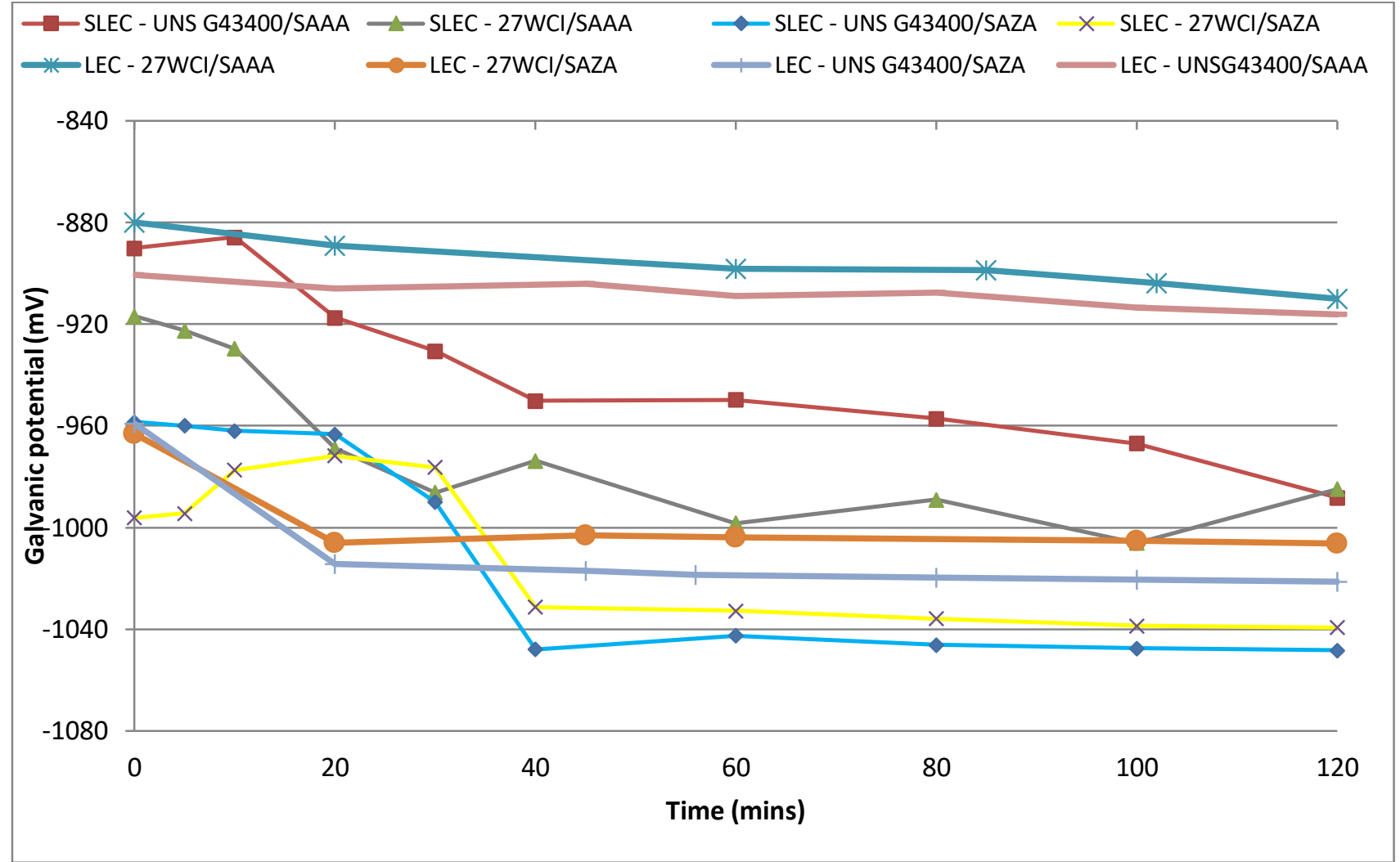

Figure 9: Measured galvanic potential with time for different galvanic couples under SLEC conditions 


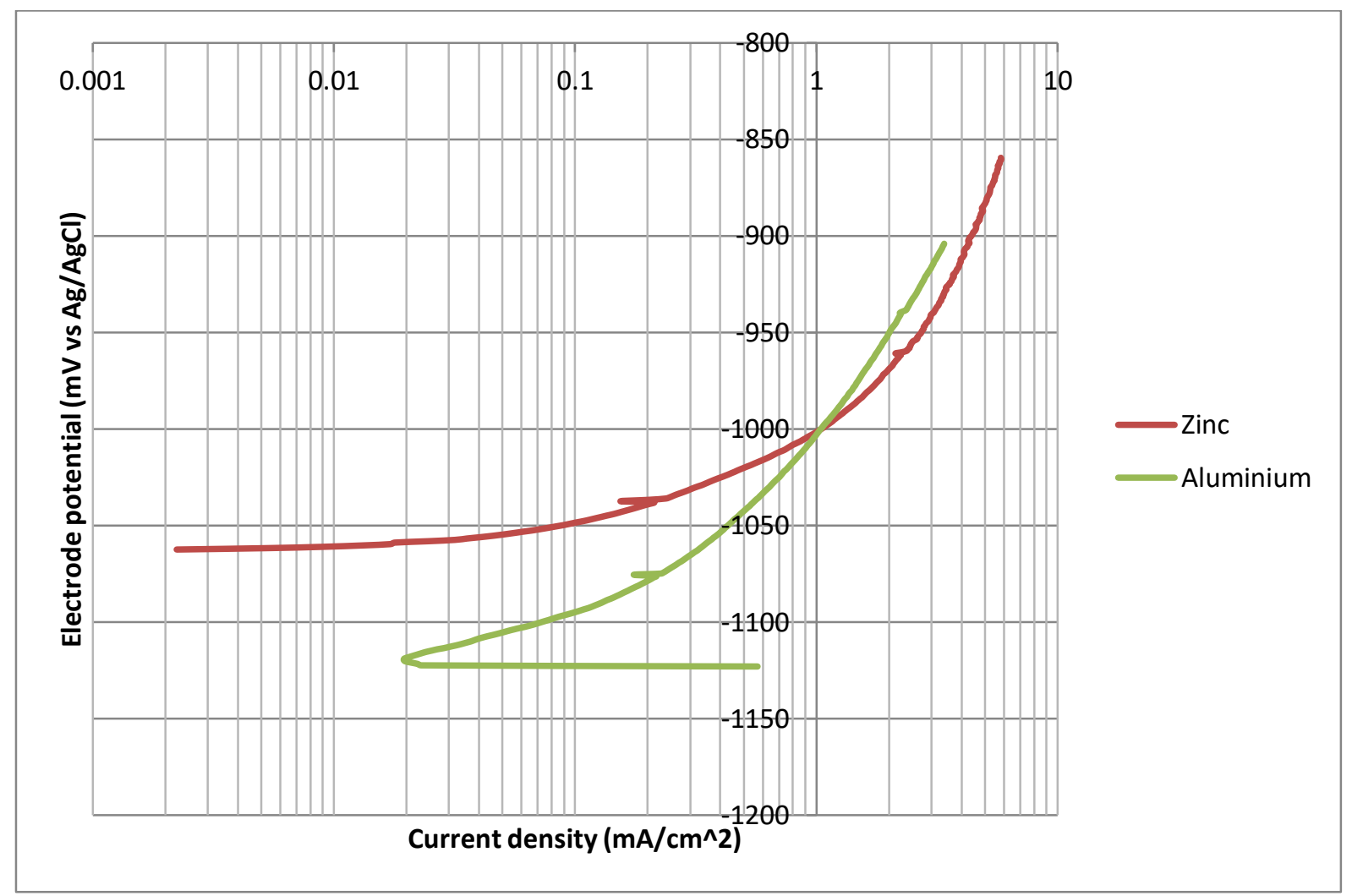

Figure 10: Anodic potentiodynamic polarisation scans for the zinc and aluminium alloys under SLEC conditions

\subsection{Macro-views of test samples}

Post-test images of the low alloy steel under SLEC conditions in FEC, ICCP, SAAA and SAZA environments are shown in Figure 11. In all test samples, a central zone is formed due to the considerable amount of erosion-corrosion damage. The central region (termed DIZ in this paper) is commonly referred to as a wear scar [25-28], which is formed as a result of high angle corrosive wear, where the sand particles impacting the surface cause small craters to form on the surface. As can be observed in Figure 11, these are formed with and without the application of CP; hence, they are predominantly a feature of the mechanical damage from the sand particles.

A concentric circle can also be observed for each of the test samples, this is commonly referred to as the "halo" region $[29,30]$. The formation of this region has been attributed to the turbulence of the fluid jet and the non-uniformity of the particle flux and sizes across the jet cross section [31]. Outwith both the wear scar and halo region is the outer area, where the sand particles impact the surface at low angles and cause sliding abrasion damage. In FEC conditions (Figure 11 - A), significant amounts of corrosion product can be observed in both the halo region and outer area. In the outer area, the corrosion product has formed small comet-like shapes on the test surface, as shown in Figure 12. This is attributed to the directionality of the fluid as it flows across the test 
surface. Cathodically protected samples (Figure $11-B, C$ and D) show no signs of corrosion product in any of the wear regions. This is demonstrated by the right hand image in Figure 12 which illustrates sliding abrasion damage only.

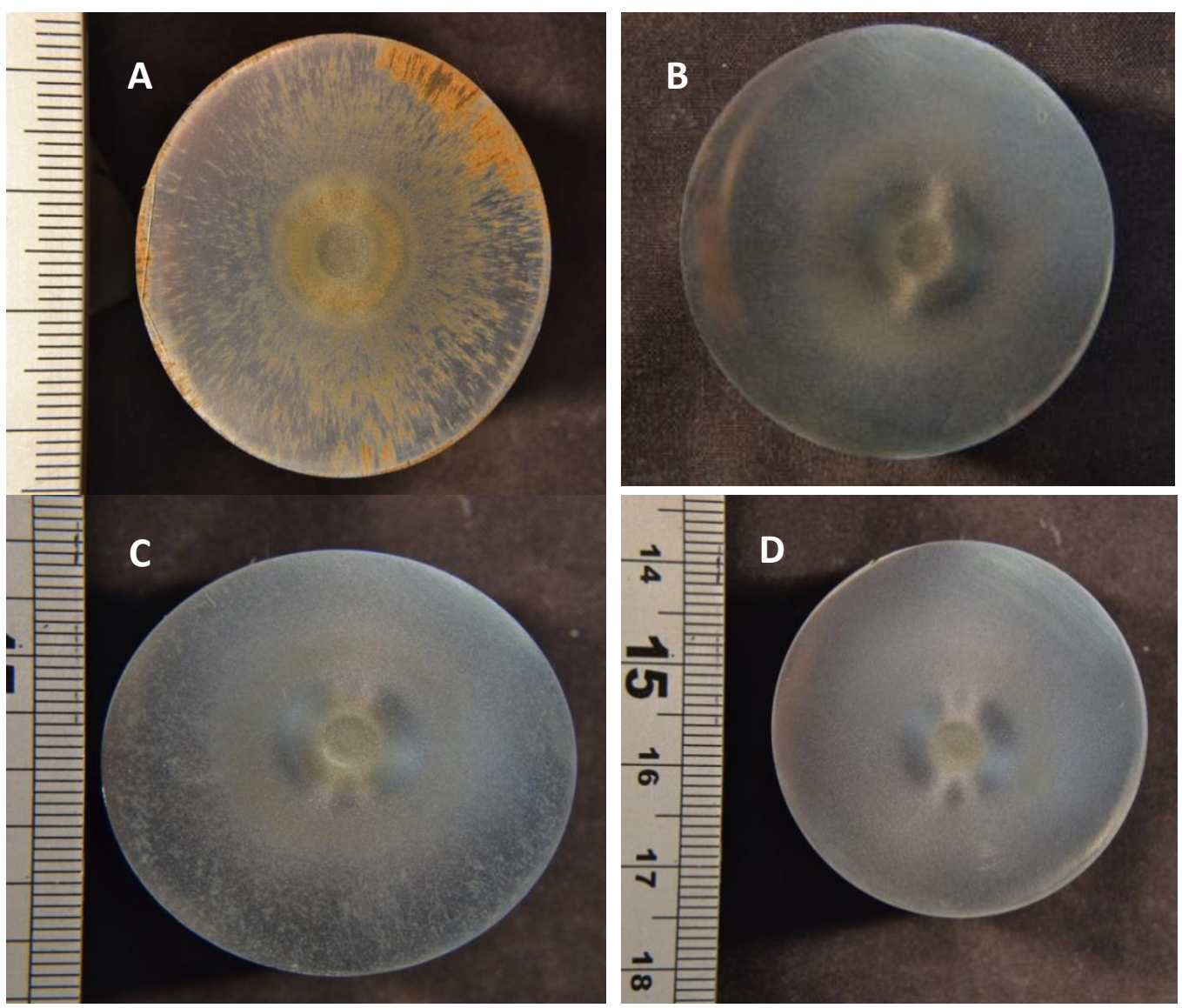

Figure 11: Post-test images of UNS G43400 under SLEC conditions (A - FEC, B - ICCP, C - SAAA, D - SAZA)
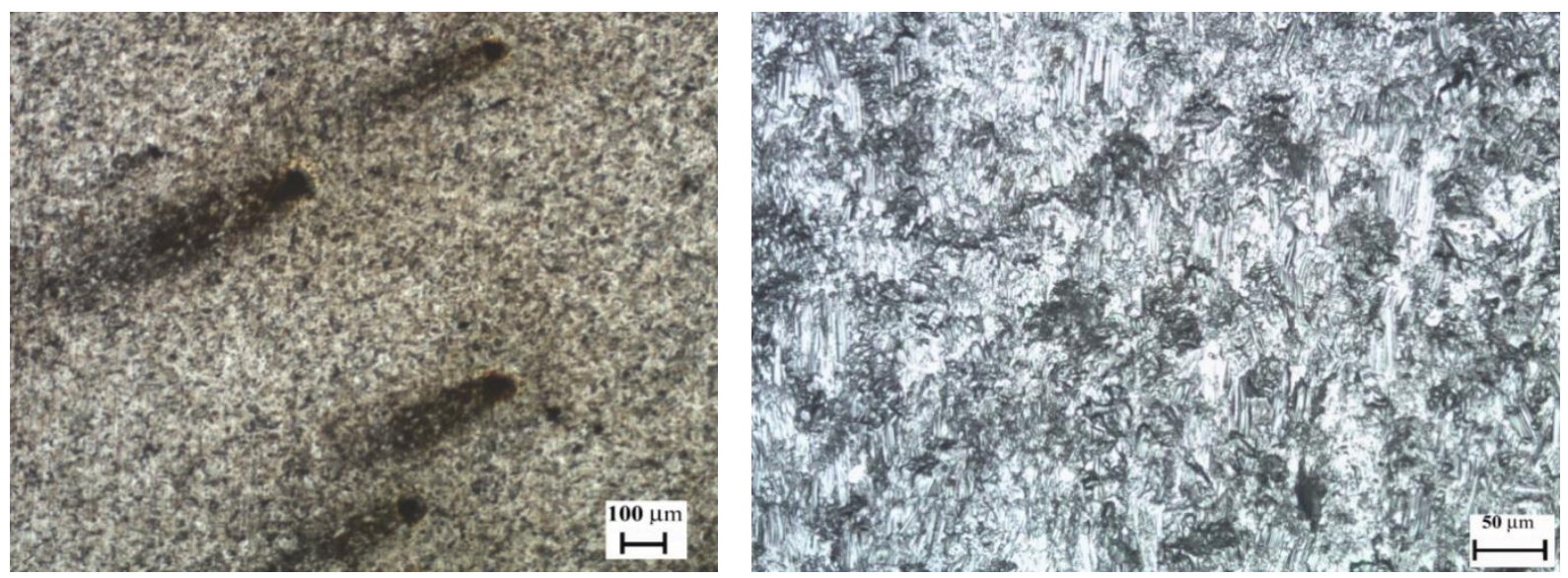

Figure 12: Comet-like pits observed in the Outer Area of UNS G43400 under FEC (SLEC) conditions (left); sliding abrasion marks in the Outer Area of UNS G43400 under ICCP (SLEC) conditions (right) 


\section{Conclusions}

- The study has shown that, in both LEC and SLEC conditions ICCP and SACP are capable of significantly reducing the corrosive wear damage for materials of limited corrosion resistance such as a low alloy steel and white chromium cast iron. As expected no discernible effects were found for a material of high inherent corrosion resistance superduplex stainless steel.

- The use of SACP therefore provides a relatively simple strategy for exploiting materials that possess relatively good mechanical wear resistance in corrosive wear situations.

- For both low alloy steel and white cast iron, the biggest reduction in material loss when CP was applied was observed in the outer area (low angle corrosive wear) but sizable reductions in the degree of attack were also observed in the DIZ for white cast iron and for the low alloy steel.

- Galvanic electrode potentials for both the low alloy steel and white cast iron showed that the zinc anode was more effective in shifting the electrode potential to more negative values compared to the aluminium anode.

\section{Acknowledgments}

The authors would like to acknowledge the support for this study, which was provided by the Weir Group PLC (WARC2011- SAA1, 2011) via its establishment of the Weir Advanced Research Centre (WARC) at the University of Strathclyde.

\section{Disclosure Statement}

The authors have no conflict of interest.

\section{References}

[1] C. I. Walker and G. C. Bodkin, "Empirical wear relationships for centrifugal slurry pumps Part 1: Side-liners," Wear, vol. 242, no. 1-2, pp. 140-146, 2000.

[2] C. I. Walker, "Slurry pump side-liner wear: Comparison of some laboratory and field results," Wear, vol. 250-251, no. PART 1, pp. 81-87, 2001.

[3] D. López, N. Alonso Falleiros, and A. Paulo Tschiptschin, "Effect of nitrogen on the corrosionerosion synergism in an austenitic stainless steel," Tribol. Int., vol. 44, no. 5, pp. 610-616, 2011.

[4] M. Aminul Islam, Z. N. Farhat, E. M. Ahmed, and A. M. Alfantazi, "Erosion enhanced corrosion and corrosion enhanced erosion of API X-70 pipeline steel," Wear, vol. 302, no. 1-2, pp. 1592-1601, 2013.

[5] R. Malka, S. Nešić, and D. A. Gulino, "Erosion-corrosion and synergistic effects in disturbed liquid-particle flow," Wear, vol. 262, no. 7-8, pp. 791-799, 2007.

[6] V. A. D. Souza and A. Neville, "Corrosion and synergy in a WC-Co-Cr HVOF thermal spray coating - Understanding their role in erosion-corrosion degradation," Wear, vol. 259, no. 1-6, pp. 171-180, 2005. 
[7] T. Hodgkiess, A. Neville, and S. Shrestha, "Electrochemical and mechanical interactions during erosion-corrosion of a high-velocity oxy-fuel coating and a stainless steel," Wear, vol. 233235, pp. 623-634, 1999.

[8] L. T. Popoola, A. S. Grema, G. K. Latinwo, B. Gutti, and A. S. Balogun, "Corrosion problems during oil and gas production and its mitigation," Int. J. Ind. Chem., vol. 4, no. 1, pp. 1-15, 2013.

[9] P. Rajeev, A. O. Surendranathan, and C. S. N. Murthy, "Corrosion mitigation of the oil well steels using organic inhibitors - A review," J. Mater. Environ. Sci., vol. 3, no. 5, pp. 856-869, 2012.

[10] A. Neville and C. Wang, "Erosion-corrosion of engineering steels-Can it be managed by use of chemicals?," Wear, vol. 267, no. 11, pp. 2018-2026, 2009.

[11] J. H. Morgan, Cathodic Protection, 2nd ed. NACE International, 1987.

[12] R. W. Revie and H. H. Uhlig, Corrosion and Corrosion Control: An Introduction to Corrosion Science and Engineering, Fourth Edition. 2008.

[13] C. Batt, J. Dodson, and M. J. Robinson, "Hydrogen embrittlement of cathodically protected high strength steel in sea water and seabed sediment," Br. Corros. J., vol. 37, no. 3, pp. 194198, 2002.

[14] R. Heidersbach, Metallurgy and corrosion control in oil and gas production. Wiley, 2010.

[15] A. Neville and T. Hodgkiess, "Characterisation of high-grade alloy behaviour in severe erosioncorrosion conditions," Wear, vol. 233-235, pp. 596-607, 1999.

[16] M. Jones and R. J. Llewellyn, "Erosion-corrosion assessment of materials for use in the resources industry," Wear, vol. 267, no. 11, pp. 2003-2009, 2009.

[17] S. S. Rajahram, T. J. Harvey, and R. J. K. Wood, "Erosion-corrosion resistance of engineering materials in various test conditions," Wear, vol. 267, no. 1-4, pp. 244-254, 2009.

[18] A. Neville and X. Hu, "Mechanical and electrochemical interactions during liquid-solid impingement on high-alloy stainless steels," Wear, vol. 251, pp. 1284-1294, 2001.

[19] L. Giourntas, T. Hodgkiess, and A. M. Galloway, "Comparative study of erosion-corrosion performance on a range of stainless steels," Wear, vol. 332-333, pp. 1051-1058, 2015.

[20] R. C. Barik, J. A. Wharton, R. J. K. Wood, K. S. Tan, and K. R. Stokes, "Erosion and erosioncorrosion performance of cast and thermally sprayed nickel-aluminium bronze," Wear, vol. 259, no. 1-6, pp. 230-242, 2005.

[21] F. Brownlie, T. Hodgkiess, A. Pearson, and A. M. Galloway, "Effect of nitriding on the corrosive wear performance of a single and double layer Stellite 6 weld cladding," Wear, vol. 376-377, 2017.

[22] T. Bellezze, G. Roventi, and R. Fratesi, "Localised corrosion and cathodic protection of $174 \mathrm{PH}$ propeller shafts," Corros. Eng. Sci. Technol., vol. 48, no. 5, pp. 340-345, 2013.

[23] L. Giourntas, T. Hodgkiess, and A. M. Galloway, "Enhanced approach of assessing the corrosive wear of engineering materials under impingement," Wear, vol. 338-339, pp. 155163, 2015. 
[24] DNV, "Recommended Practise DNV-RP-B401: Cathodic Protection Design." 2010.

[25] F. Brownlie, C. Anene, T. Hodgkiess, A. Pearson, and A. M. Galloway, "Comparison of Hot Wire TIG Stellite 6 weld cladding and lost wax cast Stellite 6 under corrosive wear conditions," Wear, vol. 404-405, 2018.

[26] N. Andrews, L. Giourntas, A. M. Galloway, and A. Pearson, "Effect of impact angle on the slurry erosion-corrosion of Stellite 6 and SS316," Wear, vol. 320, no. 1, pp. 143-151, 2014.

[27] M. D. Bermúdez, F. J. Carrión, G. Martínez-Nicolás, and R. López, "Erosion-corrosion of stainless steels, titanium, tantalum and zirconium," Wear, vol. 258, no. 1-4 SPEC. ISS., pp. 693-700, 2005.

[28] U. Malayoglu and A. Neville, "Comparing the performance of HIPed and Cast Stellite 6 alloy in liquid-solid slurries," Wear, vol. 255, no. 1-6, pp. 181-194, 2003.

[29] L. Lapides and A. Levy, "The halo effect in jet impingement solid particle erosion testing of ductile metals," Wear, vol. 58, no. 2, pp. 301-311, 1980.

[30] V. A. de Souza and A. Neville, "Corrosion and erosion damage mechanisms during erosion corrosion of WC-Co-Cr cermet coatings," Wear, vol. 255, no. 1-6, pp. 146-156, 2003.

[31] F. W. Wood, “Erosion by Solid-Particle Impacts : A Testing Update," J. Test. Eval., vol. 14, no. 1, pp. 23-27, 1986. 